\title{
O dispositivo da sexualidade no uso da literatura escolar
}

The device of sexuality in the use of school literature

Andréa Costa da Silva ${ }^{1}$

Vera Helena Ferraz de Siqueira ${ }^{2}$

\begin{abstract}
Resumo
Neste artigo apresentamos um estudo baseado em pressupostos foucaultianos, centrado na análise dodiscurso de uma professora e de seus alunos sobre o uso de livros paradidáticos para a abordagem de questões de sexualidade em sala de aula, trazendo à baila aspectos sobre a preocupação tão atual sobre a sexualidade de jovens e crianças na escola. Levamos em consideração principalmente o conceito de "dispositivo da sexualidade", em que o tripé ensino, literatura e sexualidade é enfocado. Acionamos conceitos das fases genealógica e ética da teoria foucaultiana e alguns pressupostos da história cultural para investigar os discursos que circulam na escola, mediados pela literatura, buscando compreender como o dispositivo da sexualidade mobiliza discursos e práticas quando o assunto é discutido. $\mathrm{Na}$ análise da trama discursiva produzida pelos/as participantes, notamos o privilégio conferido às práticas de si, em que se tornam preponderantes formas de auto reflexividade inscritas nos aparatos do dispositivo da sexualidade.
\end{abstract}

Palavra-chave: Literatura escolar. Discurso. Sexualidade. Gênero. Dispositivo.

\begin{abstract}
In this article we present a study based on foucaultian assumptions, centered on the analysis of the discourses of a teacher and her students on the use of books to address sexuality for the approach in the classroom, bringing to light aspects of the current concern about the sexuality of young people and children in school. We take into account mainly the concept of "device of sexuality", in which the tripod teaching, literature and sexuality is focused. We make use of concepts from the genealogical and ethical phases

\footnotetext{
${ }^{1}$ Doutora e Mestre em Educação em Ciências e Saúde, pelo Programa de Pós-Graduação em Educação em Ciências e Saúde (NUTES / UFRJ).E-mail: acostadasilva@gmail.com

${ }^{2}$ Doutora em Educação - Columbia University (1986). Atualmente é professora associada IV da Universidade Federal do Rio de Janeiro, no Laboratório de Linguagens e Mediações do NUTES/UFRJ.E-mail:verahfs@yahoo.com.br
} 
of Foucault's theory and some assumptions of cultural history to investigate discourses that circulate in the school, mediated by literature, seeking to understand how the device of sexuality mobilizes discourses and practices when the subject is discussed. In the analysis of the discursive plot produced by the participants, we noted the privilegie conferred on selfpractices, in which predominate forms of reflexivity of self upon self, which are inscribed in the apparatuses of the sexuality device.

Keywords: Schoolliterature. Discourse. Sexuality. Gender.Dispositif.

\section{Introdução}

Ataques à discussão de temáticas voltadas à sexualidade e ao gênero na escola imperam na atualidade 3 . Podemos observar um movimento acirrado na esfera legislativa do país investindo no veto ao que foi denominado "ideologia de gênero" nos documentos educacionais, com apoio de deputados/as e vereadores/as de bancadas religiosas e de movimentos como o "Escola sem partido", evidenciando uma disputa política na sociedade brasileira entre grupos com posições antagônicas e incitando os mais variados posicionamentos de pais, educadores, movimentos sociais, entre outros.

Seffner e Picchetti (2016, p. 63) contextualizam o embate mencionado e argumentam que: “[...] gênero e sexualidade são elementos atuantes no território escolar como temas necessários para aprendizagens das novas gerações". Os autores evidenciam ainda que as escolas são espaços altamente generificados e, portanto, lugares onde o poder e a hierarquia social são representados e que nelas cabe a apresentação de tais temas em uma perspectiva não só biológica, mas também sob uma ótica histórica, cultural e politica. Acreditamos que excluir esses temas da escola é um empreendimento praticamente impossivel, haja vista que, de forma mais ou menos explícita, questões importantes na construção de identidades,

${ }^{3}$ Disponivel em: <http://www1.folha.uol.com.br/educacao/2015/06/1647528-por-pressaoplanos-de-educacao-de-8-estados-excluem-ideologia-de-genero.shtml>. Acesso em: 1 nov. 2017. 
relacionadas a marcadores de gênero, de sexualidade, de raça, etnia entre outros, continuarão inevitavelmente a ocorrer, mediados sempre por tensões e conflitos de poder. Tais questões são invariavelmente agenciadas por livros, materiais e recursos didáticos nas mais variadas situações educativas e nos parece que, neste momento de ameaças e cerceamento da liberdade docente, são essenciais trabalhos como o nosso que têm por pretensão avançar no conhecimento das possiveis articulações entre poder, construção de subjetividades e marcadores de sexualidade, em situações escolares.

A abertura oferecida pelos Temas Transversais nos anos $1990^{4}$ já buscava atender à demanda e à emergência de temáticas contemporâneas como meio ambiente, sexualidade, gênero e etnia - em sala de aula. Podemos dizer que a literatura paradidática que circula nas escolas brasileiras vem ao encontro da necessidade de inserção de temas cotidianos na sala de aula por docentes de diferentes disciplinas. Esses livros servem de suporte para o empreendimento pedagógico, por vezes direcionando a pauta de discussões em sala de aula. Assim, levando em conta a materialidade dos livros utilizados e as mediações exercidas para discutir a temática, podemos indagar: sob quais perspectivas esta educação - a educação sexual mediada pelo livro paradidático - se tornou tão específica? Ou: como construímos maneiras de ensinar a sexualidade?

Neste artigo apresentamos um recorte de pesquisa de tese baseada em pressupostos foucaultianos, em que analisamos os discursos docentes e discentes sobre o uso de livros paradidáticos para a abordagem de questões de sexualidade em sala de aula. Nomeamos "seguindo o fio do livro" o percurso percorrido para, a partir dos livros paradidáticos, através de indicações, chegarmos aos/às professores/as ${ }^{5}$ que, na época, os estavam

\footnotetext{
${ }^{4}$ Parâmetros Curriculares Nacionais-PCNs, estabelecidos pelo Governo Federal através do Ministério da Educação, em1998, trazem para o âmbito escolar discussões em torno de temáticas como pluralidade cultural, ética e sexualidade, sob a forma de Temas Transversais.

${ }^{5}$ Os dados da pesquisa maior foram obtidos através de 7 entrevistas com professores de diferentes disciplinas e de 2 grupos focais com alunos/as de alguns destes/as professores/as, de 4 escolas do município do Rio de Janeiro (públicas e particulares), no
} 
utilizando em sala de aula para discutir questões relacionadas à sexualidade, ou seja, divulgadores de diferentes editoras e a agenda de escritores nos sinalizaram quais professores e as respectivas escolas que estavam utilizando livros com foco nas temáticas observadas. Os livros paradidáticos circulam na escola de forma mais livre que os livros didáticos, uma vez que não estão inseridos no Programa Nacional do Livro Didático (PNLD); tais livros - por vezes nomeados na escola "livros de literatura", outras vezes "livros paradidáticos" -entram em sala de aula devido a necessidade da discussão de algum tema específico ou da adesão do/a docente à algum projeto educacional em desenvolvimento.

No recorte aqui apresentado, investimos na análise discursiva de entrevista feita com uma docente de escola particular do Rio de Janeiro e de um grupo focal realizado com 6 jovens ( 3 meninas e 3 meninos, com idades entre 12a 15 anos), alunos/as dessa professora. Acionamos conceitos das fases genealógica e ética da teoria foucaultiana e alguns pressupostos da história cultural na perspectiva de Chartier (1999, 2001) para investigar discursos que circulam na escola, mediados pela literatura, buscando compreender como o dispositivo da sexualidade mobiliza discursos e práticas quando o assunto é discutido.

Levando em conta aspectos que devem ser observados pelo/a pesquisador/a das ciências humanas e da educação, que invista no pensamento foucaultiano, tomamos como precaução algumas "atitudes metodológicas" oferecidas por Fischer (2012), entendendo que:

[...] nossas lutas (e pesquisas) têm sempre a ver com linguagem, já que estamos continuamente envolvidos com lutas discursivas; segunda atitude é atentar para a idéia de que palavras e coisas dizem respeito a fatos e enunciados, que a rigor são 'raros', isto é, não são óbvios, estão para além das 'coisas dadas'; terceira, que fatos e enunciados referem-se basicamente a práticas, discursivas e não discursivas [...]. (FISCHER, 2012, p. 100).

segundo semestre de 2011 e primeiro semestre de 2012.Todos/as os/as docentes entrevistados/as fizeram uso dos livros em suas atividades pedagógicas de forma voluntária 
Assim, na percepção de que somos seres envolvidos na/pela linguagem, a qual se relaciona ao poder e à constituição de sujeitos, e avançando sobre a questão, recorremos a Foucault (2006), que acrescenta:

[...] a análise do discurso, assim entendida, não desvenda a universalidade de um sentido; ela mostra à luz do dia o jogo da rarefação imposta, com um poder fundamental de afirmação. Rarefação e afirmação, rarefação, enfim, da afirmação e não da generosidade contínua do sentido e não monarquia do significante. (FOUCAULT, 2006, p. 70).

Primeiramente oferecemos breve discussão sobre o livro paradidático, sua presença e permanência no âmbito educacional, entendendo que o mesmo constitui elemento primordial para que as práticas de leitura na escola aconteçam. Levamos em conta a contribuição dos Estudos Culturais com um olhar pós-estruturalista, que nos permitiu pensar tais livros a partir das formas subjetivas e/ ou culturais que esse campo de estudos disponibiliza. Em seguida, apresentamos os pressupostos foucaultianos que balizaram o estudo, em que o conceito de dispositivo (FOUCAULT, 1994) se mostrou muito mais que um conceito operatório, nos permitindo a articulação entre os campos da literatura, sexualidade e educação, norteando nosso percurso metodológico.

Vislumbrar de forma analítica o presente educacional que investigamos implicou a observação dos discursos, suas condições de possibilidade e regras de formação, a fim de pontuar as maneiras pelas quais se torna possivel a existência dessas enunciações diversas.

\section{Paradidático: um artefato cultural para ler e ensinar na escola}

Os artefatos culturais, como os livros, inserem-se em um contexto em que poder e reconhecimento são sempre negociados. Kirchof (2008) apresenta um panorama sobre a inserção da temática da diferença na 
literatura destinada a crianças e jovens a partir dos anos 1960, quando analisa livros infantis que se detém sobre a temática:

\begin{abstract}
No Brasil, em parte devido a essa tendência internacional no campo da crítica da literatura infantil e, em parte, devido às várias políticas de inclusão adotadas pelos governos federais e estaduais dos últimos anos, percebe-se uma nítida proliferação de obras destinadas ao público infanto-juvenil cuja principal temática está diretamente ligada à questão da diferença, com a presença de temas como a velhice, a infância pobre, vários tipos de deficiência física e mental, questões de raça e de gênero, entre outros. (KIRCHOF, 2008, p. 61)
\end{abstract}

Foi apenas na segunda metade do século XX que esse novo produto cultural direcionado ao público escolar surgiu "oficialmente": "[...] é só na década de 1970 que surge a nova denominação para este tipo de livro e, consequentemente, os primeiros livros paradidáticos [...]" nos diz Melo (2004, p.15). O endosso dos pesquisadores da área faz coro com a observação de Munakata (1997), quando adverte que a nomenclatura de "livro paradidático" “[...] é um termo tipicamente brasileiro, mas agregando características parecidas com outras obras publicadas em outros países [...]". (MUNAKATA, 1997, p.102). Ao que Melo acrescenta: "Se o termo pode ser uma construção editorial recente [...], porém livros de leitura contando narrativas ficcionais com o objetivo de ensinar conteúdos curriculares não o são, na história do livro para leitura das crianças na escola" (MELO, 2006, p. 119). A autora evidencia que: “[...] paradidático não é apenas um novo termo para um determinado tipo de livro, [...] há a criação de um novo produto cultural, uma nova fórmula editorial com objetivos específicos, buscando atender à demanda de um determinado tipo de público leitor, caracterizadamente escolar" [grifo da autora] (MELO, 2006, p.121). Contrapondo os livros didáticos aos paradidáticos, afirma: "A grande diferença entre eles, no entanto, pode estar no fato daqueles darem ênfase ao trabalho com algum conteúdo do currículo escolar e destacarem, já no texto introdutório, os seus objetivos pedagógicos [...]" (MELO, 2004, p.120). Levando em conta tais pressupostos, e tomando por objeto de investigação os livros paradidáticos de educação sexual endereçados à infância, Furlani 
(2005) preocupa-se em estabelecer um paralelo entre as categorias de livros didáticos e paradidáticos. Observa que são as duas categorias mais presentes no cotidiano escolar, e acrescenta que o livro paradidático também apresenta conhecimentos, como o didático, e serve ao ensino, mas "[...] seus conteúdos relacionam-se a temáticas que tangenciam as disciplinas do currículo oficial.". Afirma ainda que os mesmos "[...] são vistos como um complemento aos livros didáticos, [...] e são elaborados especificamente para cada assunto [...]." (FURLANI, 2005, p.19). Podemos verificar que não há unanimidade no conceito do que seria a literatura paradidática; mas concordamos com a consideração de Melo (2004), de que mesmo não havendo um conceito em uníssono, o livro paradidático tem como característica primordial ser "[...] uma produção cultural com destino ao público escolar." (MELO, 2004, p. 36)

Assim, tendo em mente este público especifico, levamos em conta que os livros, apropriados pela escola, são artefatos culturais que trazem em si as marcas dos discursos e das representações que usualmente circulam no senso comum. E neste ponto recorremos à teorização de Chartier (2001), de que para a História Cultural tão importante quanto o conteúdo da obra em si, imagem e texto são elementos discursivos imprescindíveis, já que textos não são indiferentes à sua materialidade, pois ao escrevê-los o autor deixa "senhas implícitas ou explícitas" inscritas em sua obra no sentido da intencionalidade e imposição de sentidos. O que mais nos interessa nessa colocação é o entendimento do autor sobre a finalidade desses elementos, que: "[...] tendem a impor um protocolo de leitura, seja aproximando o leitor a uma maneira de ler que lhe é indicada, seja fazendo agir sobre ele uma mecânica literária que o coloca onde o autor deseja que ele esteja" (CHARTIER, 2001, p. 97). Estabelecendo uma perspectiva dinâmica e relacional nas interações com o objeto impresso, concordamos com Hébrard (apud CHARTIER, 2001, p. 37, grifo nosso), quando diz: "Colocando o acento sobre o ler mais do que sobre o livro, sobre a recepção mais do que sobre a 
posse, os pesquisadores demonstram amplamente que, na escola, não é a leitura que se adquire, mas as maneiras de ler que aí se revelam”.

Por essa via, perceber as relações entre o espaço escolar e a literatura que nela circula pressupõe considerar as práticas de produção, de circulação e de consumo dos materiais impressos, podendo-se "[...] identificar o modo como em diferentes lugares e momentos uma determinada realidade é construída, pensada, dada a ler" (CHARTIER, 1990, p. 16).

Com o olhar na historicidade das práticas e dos usos dos livros, entendemos a discussão da sexualidade como um modo de experiência historicamente singular na qual o sujeito é constituído.

\section{Aspectos metodológicos: entre discursos e práticas}

No contexto da escola em que realizamos a pesquisa o livro paradidático chega às salas de aula pelas mãos dos/as docentes que o elegem como instrumento pedagógico para discutir a sexualidade. Podemos considerar o uso da literatura escolar como elemento desencadeador de estratégias de escolha, imprimindo sentido às práticas de leitura e aos artefatos culturais dos quais os/as professores/as fazem uso. Pensando na dimensão cultural da literatura é possível percebê-la como algo maior que uma questão de contexto de uso, uma vez que: “[...] a cultura está imbricada indissociavelmente em relações de poder, derivam destas relações de poder a significação do que é relevante culturalmente para cada grupo" (VEIGANETO, 2000, p. 40). Assim, a cultura e o próprio processo cultural não são dados naturais, mas artefatos submetidos às constantes tensões e conflitos de poder no que tange às questões de sexualidade e gênero, entre outros marcadores. No mosaico de enunciados que iremos apresentar a seguir, estabelecemos um diálogo com diferentes percepções sobre o livro paradidático usado para discutir a temática da sexualidade.

Para Foucault (1988), o que a instituição pedagógica fez desde o século XVIII foi concentrar as formas de discurso sobre a sexualidade, 
estabelecendo "pontos de implantação diferentes", codificando os conteúdos, e qualificando os locutores (FOUCAULT, 1988, p.31-32). Ao observarmos os discursos sobre sexualidade devemos ter a precaução de:

\begin{abstract}
Não considerar que existe um certo domínio da sexualidade que pertence, de direito, a um conhecimento científico, desinteressado e livre, mas sobre o qual exigências do poder - econômicas ou ideológicas - fizeram pesar mecanismos de proibição. Se a sexualidade se constitui como objeto possível; e em troca se o poder pôde tomá-la como alvo, foi porque se tornou possivel investir sobre ela através de técnicas de saber e de procedimentos discursivos. (FOUCAULT, 1988, p. 93)
\end{abstract}

Assim, se a sexualidade se constituiu como objeto de poder, foi devido a um jogo de relações que a tornaram objeto possivel de conhecimento em uma rede discursiva articulada com técnicas de saber. Corroborando com este pensamento, Castro nos diz: "A sexualidade está ao lado da norma, do saber, da vida, do sentido, das disciplinas e das regulações" (CASTRO, 2009, p.58). A sexualidade seria percebida antes de qualquer coisa como um dispositivo político, em articulação com o corpo, que atua sobre a sua materialidade. No entanto, sobre o assunto incidem certas prerrogativas, uma vez que ao nomear os interlocutores possiveis para discuti-la, instituise um estatuto de especificidade: "Esta personalização, medicalização e significação do sexo, que ocorreu num momento histórico determinado, é o que Foucault denomina dispositivo da sexualidade", como sinalizado por Dreyfus e Rabinow (2005, p.188, grifo nosso]. O dispositivo, que aparece como um conceito transversal na obra de Foucault, e que engloba práticas discursivas e não discursivas, "[...] é na realidade, antes de tudo, uma máquina que produz subjetivações, e como tal é uma máquina de governo", conforme indica Agamben (2005, p. 15). Em outras palavras, ao pensarmos a noção, seja ou não referente à sexualidade, podemos entender que o dispositivo opera através de estratégias, produzindo subjetivações. Para Dreyfus e Rabinow (2005), a expressão pode se aproximar de "rede de 
inteligibilidade", pois alia poder e saber numa trama específica de análise, organizando o contexto social num conjunto de práticas.

Assim, o que temos nesse enfoque não são somente as formas sob as quais são possibilitadas condições de existência de discursos que instituem saberes e poderes, mas também como o dispositivo da sexualidade opera na constituição de individualidades, fomentando subjetividades na instituição escolar e em seus sujeitos.Trata-se, desta forma, de perceber esta "realidade" de uma forma menos objetiva, entendendo que ao optarmos por uma abordagem de base qualitativa, levamos em conta o fenômeno para além do fato, ou seja, a pesquisa qualitativa possibilita, segundo Minayo (2004), pontos imprescindiveis para que possamos perceber as diferenças que distinguem as ciências sociais das ciências físico-naturais e biológicas, pois os objetos das Ciências Sociais seriam incontestavelmente "históricos"; a segunda distinção apontada pela autora, apresenta-se na esteira da primeira e vem da "consciência histórica" do nosso objeto de estudo, ou seja, dos determinantes histórico-sociais de determinada época que nem os pensadores e filósofos conseguiriam superar; assim, existe o intrínseco vínculo estabelecido entre o pesquisador e seu objeto, no qual: “[...] tanto os indivíduos como os grupos e também os pesquisadores são dialeticamente autores e frutos de seu tempo histórico" (MINAYO, 2004, p. 21).

Com esta perspectiva, observamos que a triangulação livro, docente, aluno/a evidencia a subjetivação docente e discente mediada pela obra e também nos revela a inter-relação desses sujeitos em seus discursos e práticas na mediação que estabelecem com o livro. Assim, expectativas, visões, pontos de vista de ambos os lados foram importantes para nós; o grupo focal realizado com os/as jovens, em ambiente diferente da sala de aula, sem a mediação do/a professor/a, se insere na possibilidade de complementar a informação sobre este/a leitor/a imaginado, tanto pelo/a docente, como também pelos produtores dos livros. Desta forma, os grupos focais foram importantes para perceber as significações construídas pelos/as jovens em ambiente diferente da sala de aula, sem a mediação do/a 
professor/a. O evento do grupo focal ocorreu após as aulas em que os/as professores/as utilizaram os livros. Como já dito, nosso olhar se deteve em observar o conjunto de práticas discursivas e não discursivas

Diante do corpus obtido, tivemos como preocupação descobrir quais enunciados se distinguiam em relação aos outros ou, dito de outra maneira, buscamos perceber quais enunciados ressoavam com maior intensidade em nossos ouvidos, ganhando uma suposta autonomia. Com o aporte de Foucault descobrimos que certos enunciados possuem mais "força" que outros, não de uma maneira casual e despreocupada, mas devido a contingências de seu surgimento e circulação; tais contingências indicam como nossos objetos são construídos, e assim, ao nos preocuparmos em conhecer como a temática da sexualidade é veiculada na escola, a tônica recai sobre as condições de possibilidade de existência de determinado discurso em relação a outro, como também sobre as lacunas existentes no plano discursivo.

O dispositivo da sexualidade, discutido por Foucault (1994), nos permite visualizar tipos de normalização e formas de subjetividade presentes nos discursos investigados, pois: "O dispositivo, portanto, está sempre inscrito em um jogo de poder, estando sempre, no entanto, ligado a uma ou a configurações de saber que dele nascem, mas que igualmente o condicionam" (FOUCAULT, 1994, p. 246).

\section{Entre a confissão e a subjetivação: "Ele já contou quando perdeu a virgindade dele"}

A concepção produtiva do dispositivo da sexualidade oriundo das práticas pedagógicas pode ser percebida em sua materialidade estratégica nas ações escolares que envolvem o uso do livro paradidático sobre o assunto. Para Foucault (1994), conforme discutimos antes, os discursos sobre a sexualidade, antes de qualquer coisa, devem ser observados em sua eficácia positiva, constituída das tensões entre saber-poder e formas de 
subjetivação do sujeito. No investimento teórico do autor, observa-se a análise do modo pelo qual o ser humano governa a si mesmo e os outros através da produção de verdade. A pretensão de Foucault seria pensar uma ética, tendo como elemento norteador a relação dos indivíduos consigo mesmo, e nesse sentido as formas de subjetivação moral merecem atenção. Em sua busca histórica e filosófica o autor argumenta que a ação moral é indissociável das formas de atividade sobre si, no sentido de sistema de valores, regras e interdições. Dando luz aos conceitos de moral e ética, para Foucault a primeira seria definida como um conjunto de valores e de regras de ação que são propostos aos indivíduos e aos grupos por intermédio de diferentes aparelhos prescritivos como a família, as instituições educativas, as igrejas, os sistemas de leis, de prescrição do código moral. Já em relação à ética, seria a maneira pelo qual o indivíduo se transforma, constituindo-se o próprio sujeito moral do código (PORTOCARRERO, 2009).

A técnica de confissão, diz Foucault (1988), seria a grande produtora de discursividade sobre o sexo, como também um componente importante para a expansão da tecnologia disciplinar e para o controle dos corpos e das populações. A geração da verdade sobre o sexo não estaria livre de instâncias variadas para autorizá-la; o confessor surge como a figura que congrega os atributos necessários para que esta verdade possa ser dita, essa tecnologia do eu se reveste de circunstâncias especiais para ser proferida. De acordo com Dreyfus e Rabinow:

Para Foucault, o exame médico, tal como praticado no século XIX, assim como todas as formas circunscritas à confissão, expuseram às figuras de autoridade as fantasias sexuais mais profundas e as práticas mais ocultas do indivíduo. $\mathrm{O}$ indivíduo foi persuadido de que, através de tal confissão, era possivel conhecer a si mesmo. (DREYFUS; RABINOW, 2005, p.191).

Inscritos em mecanismos de subjetivação, a confissão e o exame agregam os ingredientes para que os sujeitos possam operar estratégias de "autogoverno". Tais dispositivos disciplinares se amparam em procedimentos pedagógicos para alicerçarem seu investimento e deste modo: "A chave para 
a tecnologia do eu é a crença de que se pode, com a ajuda de peritos, falar a verdade sobre si mesmo. Este é o princípio fundamental, não somente nas ciências psiquiátricas e na medicina, como também na lei, na educação, no amor" (DREYFUS; RABINOW, 2005, p.192).

Os procedimentos educativos na discussão da sexualidade investem em tal abordagem, na medida em que se trata de trazer o indivíduo para um aparato institucional que o faça produzir uma modalidade discursiva que estabeleça uma relação da pessoa consigo mesma, com pressupostos do autoexame. Tal assertiva tem na transformação individual seu objetivo principal, assim ao dizer-se, é conformada esta rede discursiva de significados, formas legitimas de falar e de se constituir, em paralelo ao mecanismo do confessionário, onde o confessor é o primeiro fiel depositário das culpas. A extensão do ato vai além, quando se desdobra na necessidade do vigiar-se e

punir-se (FOUCAULT, 1994), interferindo de forma significativa na subjetividade. Com a perspectiva de esclarecer a genealogia das práticas confessionais no Ocidente, Kleber Prado Filho comenta:

Quando se diz 'confissão' deve-se entender tecnologia de confissão:
conjunto imbricado de saberes e práticas relativos à subjetividade,
colocados numa relação de incitação reciproca, onde o ato de
verbalização, o exercício do discurso em relação a si mesmo, gera um
conhecimento sobre o sujeito. Ela é uma grande tecnologia de
conhecimento e subjetivação dos sujeitos inventada pelo
cristianismo, que se difundiu em variados campos da vida moderna,
presente entre nós no âmbito das relações institucionais, mas
também das relações pessoais, intimas, sempre ligada a formas de
conhecimento e de trabalho dos sujeitos sobre si mesmos. (PRADO
FILHO, 2006, p. 145)

Para este autor, a hermenêutica de si cristã, em que o conhecimento de siopera na ordem de um "trabalho sobre si" ou como base para a "transformação de si", é diferente da hermenêutica de si moderna que está comprometida com uma regularidade científica. Pensando nesses 
pressupostos, observamos as colocações da Professora Bruna ${ }^{6}$ ao nos relatar como surgiu o trabalho e a escolha do livro e sobre suas pretensões com o uso do paradidático:

Professora Bruna [...]. Aí eu falei com a coordenadora, eu falei sobre a Campanha da Fraternidade que estava falando sobre Saúde Pública e ela falou assim: "Bruna. tem uns livros aqui da Moderna [Editora] e... tem um catálogo de livros aqui e você dá uma olhada", e a partir desse catálogo eu fui ver se encontrava algum livro que sugerisse o tema da Campanhalda Fraternidade]e também proporcionasse a vontade de abordar este tema e ai encontrei esses dois livros, "O sexo: a hora é agora", estou trabalhando com o $8^{\circ}$ ano e o "Adolescente, um batepapo sobre sexo", estou trabalhando com as turmas do $9^{\circ}$ ano, são editoras diferentes, mas os dois, pela proposta estava atendendo o que eu queria com eles e também ao encontro da Campanha da Fraternidade porque é um Ensino Religioso e tinha que estar focado em algum tema da Campanha, e eram sugestões das duas Editoras para a Campanha da Fraternidade, eram livros que estavam dentro do enfoque da Campanha, como Saúde Pública, porque os dois falam a respeito dos cuidados com o corpo, cuidados com a mente, ter um corpo são[...]

A Campanha da Fraternidade de 2012 motivou a escolha e ofereceu a oportunidade para o uso do mencionado livro em sala de aula, nos conta a Professora Bruna; para ela o tema "sexualidade" agregaria os atributos que a discussão sobre Saúde Pública incorporada pela Campanha poderia levantar. A percepção de saúde nesse sentido se relaciona com a sua dimensão de cuidado, ou de forma mais específica, com a cultura do "cuidado de si", possivelmente em uma das perspectivas que são oferecidas por Foucault. Na trajetória entre a "fase genealógica" e a "fase ética" de sua obra, o filósofo transita entre os focos do saber e do poder e sua constituição

${ }^{6}$ Entrevista realizada em junho de 2012, em escola particular de cunho religioso do bairro da Tijuca-RJ.

Bruna (nome fictício) é Professora de Ensino Religioso. Usou os livros: "Sexo: a hora é agora?" e "Adolescente: um bate-papo sobre sexo" nas turmas de $8^{\circ}$ e $9^{\circ}$ anos do Ensino Fundamental. Em ambas as obras, com foco em temas voltados à sexualidade juvenil, o texto informativo e o ficcional se misturam. 
nas práticas, levando em conta também a dimensão de subjetivação do sujeito consigo mesmo e em relação com o outro. O conjunto de técnicas ascéticas atribuídas ao cristianismo evidencia-se na análise feita por Foucault da formação e transformação em nossa cultura das relações consigo mesmo, com sua estrutura técnica e seus efeitos de saber. Ao comentar o lançamento dos livros História da Sexualidade II e III, e o possivel deslocamento em seus temas, o filósofo esclarece:

Talvez tenhamos mudado de perspectiva, girado em torno do problema, que é sempre o mesmo, isto é, as relações entre o sujeito, a verdade e a constituição da experiência. Procurei analisar de que modo domínios como os da loucura, da sexualidade, da delinqüência podem entrar em um certo jogo da verdade e como, por outro lado, através dessa inserção da prática humana, do comportamento, no jogo da verdade, o próprio sujeito é afetado. Era este o problema da história da loucura, da sexualidade. (FOUCAULT, 2006, p. 289)

Com tal esclarecimento, Foucault endossa que sua preocupação seria cada vez mais com as tecnologias da dominação individual, na história do modo como um indivíduo atua sobre si mesmo, isto é, com a "tecnologia do eu [si]".

A professora Bruna evidencia tal aspecto comentado por Foucault quando questionada sobre como se realiza a avaliação do trabalho com o livro paradidático:

Professora Bruna: [...] a minha avaliação vai ao encontro aos temas iluminadores do Ensino Religioso que no momento são da perspectiva do menino do $8^{\circ}$ ano, conhecer-se a si mesmo, que é o gancho no início do $8^{\circ}$ ano, conhecer-se enquanto pessoa, primeiro exercitar essa questão que primeiro eu preciso me conhecer, para tentar até ver o outro de uma outra maneira, se aceitar como é, valorizar o seu corpo, né? Valorizar as questões mesmo das coisas que o rodeiam, e aí o gancho dessa avaliação do livro, ela vai ao encontro desse tema iluminador que foi a proposta do $1^{\circ}$ bimestre e do $2^{\circ}$ bimestre, daí vem a questão da religiosidade que é essa questão dele enquanto conhecer-se melhor, gostar do outro. Gostar do outro, para quê? Gostar do outro, quando? Né? E por quê? E dai vão surgindo as respostas [...] 
A professora se preocupa com a constituição moral desse sujeito, seu/sua aluno/a, encorajando uma abordagem voltada para a ação reflexiva, em que os atos voltados a "analisar-se", a tomar para si o próprio destino ficam mais evidentes. Tal pensamento é possivelmente oriundo da crença em uma possivel essência constitutiva da subjetividade, que sustenta o sujeito e encontra respaldo no saber dito científico, preponderante para a suposta racionalidade.

No desdobramento dessas discussões em sala de aula, os/as alunos $/$ as $^{7}$ da professora Bruna nos relatam:

Mediadora: E vocês acham importante, o que vocês acham? Vocês gostam da aula, qual a opinião de vocês sobre o assunto e sobre o trabalho aqui?

Grupo 18:

Aluna Melissa: Eu acho bem interessante, até porque a gente reflete aqui, antes eu não pensava em fazer isso, agora eu posso melhorar, consertar as minhas atitudes...

Aluno Mauro: Eu acho isso essencial para orientação do adolescente, pré-adolescente mesmo, porque isso vai surgir na vida dele e a gente não pode deixar passar batido...

Aluna Mirtes: E às vezes nem os pais têm essa liberdade para falar sobre isso, né? E aí todo mundo fica muito quieto, mas não é para ficar quieto, porque isso vai surgir em algum momento e o adolescente tem que estar preparado para as coisas da vida...

Aluna Melissa: E o adolescente também tem muitas dúvidas...

Frente a tais enunciados, não podemos esquecer que o debate em torno da questão da sexualidade na escola se apresenta de forma

\footnotetext{
${ }^{7}$ Grupo-focal com alunos/as da Professora Bruna. Os/as alunos/as receberam nomes fictícios
} 
diferenciada em relação a outros assuntos que por vezes emergem na pauta escolar. A sexualidade foi apropriada como um "problema oficial" a ser discutido dentro da escola após a implementação dos PCNs. A "colocação do sexo em discurso", como nos situa Foucault (1988), evidencia a inquietação com o assunto, acionando-se estratégias de poder e saber que configuram o que pode ser discutido e como fazê-lo no espaço escolar. O aspecto reflexivo através do qual este "dizer-se" é incorporado nas instâncias pedagógicas evidencia que tal estratégia busca uma produtividade em que os mecanismos da visibilidade constituem a relação que o "sujeito de si" estabelece com sua consciência.

O dispositivo da sexualidade incita a "experiência de si" e encontra respaldo nas formas narrativas do "dizer-se", comuns nas ações pedagógicas e terapêuticas incorporadas pela escola; tal conformação educativa adquire valoração quando percebida como constituinte de subjetividades, principalmente no que se refere ao aspecto moral. Assim, a constituição de um sujeito reflexivo é privilegiada para colocar "o sexo em discurso", uma vez que este aparato oferece os mecanismos de visibilidade/reflexividade tão caros à conformação da subjetividade do sujeito nos preceitos de uma sexualidade normativa em que os projetos de uma "juventude ideal" encontram respaldo.

Esse investimento em ações educativas que produzam um arcabouço narrativo muito peculiar nos faz lembrar a "produtividade tática" e a "integração estratégica", inerentes ao campo discursivo em que a sexualidade é situada por Foucault (1988). Tal aspecto é evidenciado pelo autor quando indica a necessidade de privilegiar a observação da conjuntura e da correlação de forças em que estes discursos se engendram, bem como os efeitos reciprocos de poder e saber que proporcionam. Deixa-se assim de lado a preocupação precípua em supor de qual teoria implícita derivam ou que divisões morais ou ideológicas esses discursos estabelecem. Observamos também no grupo-focal os/as alunos/as da professora Bruna comentando sobre suas aulas e as do Professor de Artes Cênicas: 
Mediadora: Normalmente nas aulas vocês perguntam sobre questões de sexualidade, sem ser as aulas da Bruna?

Todos os/as alunos/as: Não!

Aluno Mauro: [...] tem com os professores que eu tenho mais intimidade, os alunos da minha sala também tem, que é a professora Helena e a Elenita, de Ciências...

Aluno Murilo: É legal, as aulas, porque sempre tem um debate sobre o assunto. O assunto surge, cada um vai dando sua opinião é legal porque ninguém fica quieto, todos querem mostram sua opinião [...]

Aluno Mauro: Tem um outro professor que trabalha junto com ela [Bruna], é o Wilson, ele é professor de teatro. Ele, assim, não discute como a Bruna, mas ele também dá uma liberdade assim

Aluna Melissa: Ele dá tanta liberdade quanto [...] eu acho que ele dá abertura, ele mesmo até dá a opinião dele...

Aluna Mirtes: Ele já contou quando ele perdeu a virgindade dele, que ele perdeu com 14 anos e que foi muito ruim e essas coisas assim...

Aluno Murilo: Assim, debate, é mais em relação à Bruna, também não é a matéria dele, mas mesmo assim ele dá liberdade para falar o que quiser...

Aluno Michel: E depois desse debate, ele deu um conselho pra gente não apressar logo o sexo, por que não [viver] umas etapas, mais umas coisas que surgem antes do sexo, não é chegar e fazer sexo, sabe? É um processo, não precisa apressar as coisas.

Confiança e incerteza permeiam a pauta dessa discussão que se ampara em um arcabouço narrativo e em sua ação reflexiva como dispositivos da sexualidade. A relatada declaração do professor sobre a perda da sua virgindade, recebe o tom confessional necessário e se inscreve nos mecanismos de subjetivação do sujeito. Como esfera da subjetividade, não nos cabe aqui classificar a prática educativa realizada ou estabelecer juizo de valor. O que destacamos é que os processos de subjetivação evidenciados inscrevem-se nos aparatos do dispositivo da sexualidade em que se torna preponderante o “dizer-se”. Na construção de ações reflexivas de cunho moral, por vezes a prática educativa investe em formas de 
experiência de si nas quais os indivíduos podem se tornar "sujeitos de si", evidenciando aspectos valorizados pela moralidade cristã. Sabemos que esta é uma face do dispositivo da sexualidade oriunda de ações que medeiam e constituem as subjetividades daqueles/as que estão imbricados nestes processos. No enunciado em análise, o dispositivo da sexualidade atua trazendo para discussão um conhecimento sobre si, procurando obter um efeito educativo transformador, como sugere Filho (2006). A hermenêutica de si moderna está comprometida com o conhecimento de si, que opera na ordem de um "trabalho sobre si" ou como base para a "transformação de si"; seria na produção deste movimento circular que o dispositivo da sexualidade atua.

\section{Conclusão}

Neste artigo concentramos nossa análise nos discursos docentes e discentes sobre as práticas pedagógicas que ocorrem na escola com a mediação de livros paradidáticos para discutir o tema. O acionamento do dispositivo da sexualidade foi de grande valia para visualizar esta rede especifica de análise, localizando as relações entre poder e saber e a produção de subjetividade inerente a elas, com a mediação do livro paradidático. Foi possivel vislumbrar o privilégio conferido às práticas de si, imbricadas nas técnicas de subjetivação do sujeito, no vinculo histórico entre subjetividade e verdade. Os processos de subjetivação, nesse caso, inscrevem-se em práticas diversas em que as preocupações estão ligadas à legitimidade dos interlocutores (sejam os/as docentes ou os/as jovens, investidos/as em sistemas de confiança), bem como em processos de "verse", "ouvir-se" e "narrar-se" que fogem aos preceitos da hermenêutica cristã e possivelmente estariam mais bem inscritos na centralidade do "dizer verdadeiro" sobre o tema, pontuando as preocupações daqueles/as que pensam a temática da sexualidade na escola e com ela atuam. Tal condução se ampara em pressupostos preventivos, investindo nas práticas da cultura 
do "cuidado de si", como evidenciam os enunciados aqui discutidos. Apontam para abordagens que percebem a questão da sexualidade da escola na perspectiva produtiva, "positiva" do discurso, com ações voltadas a explicar, esmiuçar, não deixar nada velado para que não se produzam desdobramentos "negativos".

A "autorização" auferida pelos PCNs, por algum projeto institucional ou simplesmente pelo currículo, confere o passaporte para que as vontades docentes sejam exercidas. Trazer para sala de aula temas "polêmicos", como questões sobre sexualidade, requer do/a docente discernimento, pois ao contrário do que ocorre com o livro didático, a incorporação da literatura paradidática se deve geralmente à escolha pessoal do/a docente ou à adesão a determinado projeto desenvolvido na instituição escolar. Em outras palavras, a escolha e o modo de desenvolvimento das ações pedagógicas têm um caráter mais livre e eletivo do que as atividades atreladas ao livro didático, pois o livro didático agrega conteúdo do currículo formal, trabalhado de forma quase obrigatória, o que não ocorre com o paradidático, inclusive devido à natureza "transdisciplinar" de sua existência.

Os resultados do estudo apontaram certo direcionamento e fechamento dos significados quando a temática posta em discussão é a questão da sexualidade. Como indica Lacerda (2012) tal abordagem se sobrepõe a outros aspectos que poderiam ser observados, como por exemplo, a dimensão do prazer pela leitura, ou a oportunidade de contato com "o malestar", um desencadeador de subjetividades no ser humano.

No entanto, se fôssemos pensar que docentes e jovens caem somente na "armadilha" da discussão restritiva sobre sexualidade, excluindo outras significações, ficaria evidenciado o modo uníssono como as apropriações são feitas e sua convergência para o senso comum. Ao invés, preferimos acreditar em outras leituras e nas possiveis subjetivações em que outros sentidos podem ser construídos.

Para finalizar, relembrarmos a preocupação tão atual sobre a sexualidade de jovens e crianças na escola, e enfatizamos o quão 
inapropriado se torna o policiamento ou o cerceamento de assuntos na esfera escolar, pois jovens e crianças, bem como os/as docentes, não estão isentos dos processos de poder e significação que permeiam as discussões sobre sexualidade e gênero na escola. Assim, a discussão sobre se devemos ou não trazer à baila temas tão caros à subjetividade humana na escola deve ir além de um embate de forças de viés ideológico, ou como refletem Seffner e Picchetti (2016, p. 77) referindo-se ao tema: "De modo muito profundo essas questões estão inseridas no campo dos direitos humanos, ou seja, elas dizem respeito à vida política no espaço público e à administração de poder e de oportunidades entre pessoas ".

\section{Referências}

AGAMBEN, Giorgio. O que é um dispositivo? Outra travessia, Santa Catarina, 2005.Disponívelem:<http://www.periodicos.ufsc.br/index.php/Outra/articl e/view/12576/11743>.Acesso em: 13 dez. 2012.

BRASIL. Secretaria de Educação Fundamental. Parâmetros curriculares nacionais: terceiro e quarto ciclos: apresentação dos temas transversais. Brasília: MECSEF, 1998.

CASTRO, Egardo. Vocabulário de Foucault: um percurso pelos seus temas, conceitos e autores. Belo Horizonte: Autêntica, 2009.

CHARTIER, Roger. A ordem dos livros. 2. ed. Brasília, DF: UNB, 1999. Práticas da leitura. 2. ed. São Paulo: Estação Liberdade, 2001. - A história cultural: entre práticas e representações. Rio de Janeiro: Bertrand Brasil, 1990.

DREYFUS, Hubert; RABINOW, Paul. Michel Foucault. Uma trajetória filosófica. Para além do estruturalismo e da hermenêutica. Rio de Janeiro: Forense Universitária, 2005.

FISCHER, Rosa Maria Bueno. Trabalhar com Foucault - Arqueologia de uma paixão. São Paulo: Autêntica Editora, 2012.

FOUCAULT, Michel. A ordem do discurso. 13. Ed. São Paulo: Loyola, 2006. . História da sexualidade I. São Paulo: Graal, 1988.

Vigiar e punir: nascimento da prisão. 11. ed. Petrópolis: Vozes, 1994.

FURLANI, Jimena. O Bicho vai pegar! - um olhar pós-estruturalista à Educação Sexual a partir de livros paradidáticos infantis. 2005. $272 \mathrm{f}$. Tese de Doutorado (Doutorado em Educação) - Universidade Federal do Rio Grande do Sul, Rio Grande do Sul, 2005.

KIRCHOF, Edgar Roberto; SILVEIRA, Rosa Maria Hessel. Professoras moralizadoras, normalizadoras ou ausentes: a literatura infantil retratando as diferenças. Anuário de literatura, v. 13, n. 2, p. 56-75, 2008. Disponível 
em:<http://www.periodicos.ufsc.br/index.php/literatura/issue/current/sho wToc>. Acesso em: $21 \mathrm{dez} .2010$.

LACERDA, Nilma Gonçalves. ¿ Una asignatura em La escuela, La literatura? - Matéria de escola, a literatura? Noticias, Rio de Janeiro, v.8, p.9, ago. 2012. MELO, Elizabeth. Amorim de Almeida. Estudo de uma coleção paradidática de língua portuguesa. In: FERREIRA, Sandra de Almeida. Livros, catálogos, revistas e sites para o universo escolar. Campinas: Mercado das Letras, 2006. P.115-136.

MELO, Elizabeth. Amorim de Almeida. Livros paradidáticos de Lingua Portuguesa para crianças: uma formula editorial para o universo escolar. 2004. 156f. Dissertação (Mestrado em Educação) - Faculdade de Educação, UNICAMP, Campinas, 2004.

MINAYO, Maria Cecília de Souza. O desafio do conhecimento: pesquisa qualitativa em saúde. São Paulo: Hucitec-Abrasco, 2004

MUNAKATA, Kazumi. Produzindo livros didáticos e paradidáticos. 1997. 267 p. Tese (Doutorado). Pontifícia Universidade Católica de São Paulo, São Paulo, 1997.

PRADO FILHO, Kleber. Uma genealogia das práticas de confissão no Ocidente. In: RAGO,Margareth; VEIGA - NETO, Alfredo (org.). Figuras de Foucault. Belo Horizonte, MG,2006.p. 139-153.

PORTOCARRERO, Vera. As ciências da vida: de Canguilhem a Foucault. Rio de Janeiro: Ed. Fiocruz, 2009.

RIBEIRO, Marcos. Adolescente: um bate-papo sobre sexo. São Paulo: Moderna, 2008.

SEFFNER, Fernando; PICCHETTI, Yara de Paula. A quem tudo quer saber, nada se lhe diz: uma educação sem gênero e sem sexualidade é desejável?

Reflexão e Ação (Online), v. 24, p. 61-81, 2016. Disponível em:

<https://online.unisc.br/seer/index.php/reflex/article/view/6986

WENDEL, Fernanda. Sexo: a hora é agora? O que você precisa saber para tomar esta decisão. São Paulo: Ática, 2007.

VEIGA-NETO, Alfredo. Michel Foucault e os estudos culturais. In: COSTA, Marisa Vorraber. (Org.). Estudos culturais em educação. Porto Alegre: Editora da UFRGS, 2000. p.37-69. 